\title{
USING COOPERATIVE TEACHING TECHNIQUES IN ENGINEERING COURSES. THE JIGSAW CASE
}

\author{
Maria-Cristina Marinescu ${ }^{1}$ and Jose L. Marzo ${ }^{2}$ \\ ${ }^{1}$ CASE, Barcelona Supercomputing Center, Jordi Girona, 29, 08034, Barcelona, Spain \\ ${ }^{2}$ Institute of Informatics and Applications, University of Girona, Plaça Sant Domenec 3, 17004, Girona, Spain
}

\begin{abstract}
Students everywhere are increasingly expecting to learn content that is immediately relevant to the degree they are preparing for. The negative implication of this is that they generally lack the motivation to study the fundamentals and understand in-depth material that they may not yet see the use for. Based on our previous experience with inquiry-based learning methodologies, and given the course content and the number of students in class we felt that a collaborative inquiry-based approach would encourage students to actively participate in their learning, motivate them to learn differently than in traditional ways, and inspire them to share information with their classmates. Results using the Jigsaw methodology show that some of the more positive effects were teamwork and "being forced to understand and prepare well enough to be able to explain clearly to your colleagues". On the negative side, some students found the number of presentations to be excessive and some thought that they knew less about the material that they had not prepared themselves than they would have known had they followed a traditional teaching method.
\end{abstract}

\section{KEYWORDS}

Autonomous Learning, Collaborative Learning, Active Learning, Jigsaw

\section{INTRODUCTION}

The lack of general technical motivation of undergraduates in the third year of the Design and development of videogames degree at the University of Girona, Spain, triggered our search for non-traditional teaching-learning techniques to make them more interested and increase class participation. An important factor in our decision was the desire to complement the purely technical skills students acquire during the course with skills directed to the effective monitoring, selection, and analysis of information, decision-making in complex problems, and teamwork.

Based on our previous experience with inquiry-based learning methodologies, such as problem-based learning, course content, and the number of students in class, we considered that a collaborative inquiry-based approach may work well. After further reading we decided to adopt the Jigsaw method.

We set up the experiment with third year undergraduates in the Cloud computing and distributed systems for videogames course'. This is a rather technical course in the curriculum of the videogame design and implementation specialization, but it lends itself to the learning various topics independently. One of the concerns with the Jigsaw method - as with most collaborative methods - is that, after a certain age, students are already settled into their roles as leaders or followers which, in turn, could make it harder for them to work in collaborative environments that lack hierarchy. This is yet another reason why we chose to see how third year students would adapt to this methodology. To limit the possibility of negative outcomes for some of the students, we decided to apply the Jigsaw method to only part of the course contents - specifically to Optical Networking, which stands for an eighth of the course content and grade. The idea is to later validate these results with even older students in a course of the Master's program at another Spanish university, in which 10 to 25 students typically register.

This paper is organized as follows: Section II is an abbreviated introduction to the literature of collaborative and inquiry-based methods. Section III presents our case study and Section IV introduces the method, including the questionnaires that students were asked to fill out after each Jigsaw session. Results are presented in Section V. Section VI draws conclusions and sketches out future work. 


\section{BACKGROUND}

\subsection{Collaborative Learning}

Collaborative learning techniques are based on student cooperation to achieve a common goal. This class of techniques presents the student with the challenge of explaining concepts to fellow groupmates who may not know or understand the material. While doing this, students develop their communication, argumentation, and debating skills. Cooperative learning is based on the premise that the students can learn better by doing and by working with each other than from the instructor presentations, Slavin, 1995) (McConnel, 1996) (Jones, 2007) and (Pow Sang, 2016).

In collaborative learning environments, students do not rely solely on their teachers. They are not motivated only by their teachers' approval or praise and they do not wait for correction, advice, or instruction on part of their instructors to advance. Instead, the focus is shifted to working in pairs and groups, and the teacher acts as a facilitator rather than a deliverer of knowledge (Zarei, 2016).

\subsection{Active and Inquiry-Based Learning}

Active learning is intended to address the problem of passive students usually losing concentration 10-15 minutes into a 50-minute lecture (Stuart, 1978). The methodology is based on the hypothesis that if a student is actively involved in reading, writing, discussing, problem solving, or interacting via questions, he/she will pay more attention throughout the class.

Inquiry-based learning focuses on the student investigating a question or a problem and using evidence-based reasoning and creativity to obtain the answers, which he/she then must present and defend (Guido, 2017). From the teacher's viewpoint, this methodology is supposed to not only create curiosity about a subject, but also to elicit critical thinking and understanding on part of the students. The tools at the teacher's disposal are usually guided research, document analysis, and question-and-answer sessions, and they may be used in the form of i) case studies, ii) group projects, iii) research projects, iv) field work - especially for science lessons, and/or v) unique exercises tailored to the students' needs (16). In this work, we mainly address point iv).

\subsection{Jigsaw}

Jigsaw is a collaborative inquiry-based learning technique proposed by (Aronson, 1978). It consists of dividing the learning material into different tasks and the class into different teams, each containing a number of students usually equal to (or greater than) the number of tasks. Each student in a Jigsaw team will have to perform one of the tasks, which will eventually be integrated by the team to complete the learning process. The methodology iterates between task-based and team-based work. Task-based work is performed in groups of increasing size, starting with individual work and ending with all the students that were assigned to a specific task contrasting and complementing their understanding to reach common ground. After each such phase, each student returns to their corresponding Jigsaw team and presents a report.

This technique takes advantage of learning by teaching. In learning by teaching, Student A teaches Student B about a particular subject. Not only does B learn from this process - and from A's knowledge, but A also learns as he must clearly articulate his understanding to B.

The results of a number of investigations support the positive impact Jigsaw has during the teaching/learning process. In (Sharan, 1980), a study on the effect the Jigsaw Classroom method has was carried out on learners' attitudes and achievements. Jigsaw helped create interdependence among learners as a result of the learning task being divided up amongst them. The results of the study showed a significant change in learners' attitudes towards their fellow classmates as well as a heightened perception of self.

Jigsaw also shows the potential to increase learners' active participation and communication skills (Sahin, 2010). (Durmus, 2008) reports that the effect of Jigsaw on students' performance leads them to conclude that it should be used in all phases of education thanks to its positive influence as compared to traditional learning. In (Felder, 1998), the sequential and global dichotomy learning style, among others, is defined. Most formal education involves presenting material in a logically ordered progression. Some students are comfortable with 
this system; they learn sequentially, mastering the material (more or less) as it is presented. Others, however, may be lost for weeks, until suddenly they "get it". Jigsaw helps to combine the two types of learning and the benefits of both.

In all such studies, the Jigsaw technique encourages students to better participate in their learning, motivates them to learn larger amounts of material faster than in traditional ways, and inspires them to share information with their classmates.

\section{OUR APPROACH}

\subsection{Case Study}

We developed the present study with the 12 third year undergraduates registered in the Cloud computing and distributed systems course of the "Design and development of videogames" specialization during the 2019 Spring quarter. In many engineering disciplines, the learning process is based on incrementally building new knowledge on top of concepts that are already fully understood. This makes the process of selecting a set of topics that could be independently studied a major challenge. We selected Optical Networking because it can be more easily split into independent subtopics as follows:

- Optical fiber (transmission, type of fibers, wavelength multiplexing)

- Optical components (multiplexors/demultiplexers and transponders, amplifiers and switching fabrics)

- Types of optical networks ("circuits", bursts, packets)

These topics can be studied initially in any order, then they could be used as the Jigsaw pieces. The learning process starts with online content search based on a set of keywords that the teacher provides for each subtopic.

\subsection{Organization of the Experiment}

(Felder, 2003) states that learning techniques should focus on structured cooperative learning that targets five criteria: positive interdependence, individual accountability, face-to-face interaction, the use of appropriate interpersonal skills, and self-assessment towards the continuing goals. These criteria form the basis for planning and managing cooperative learning methods that have been identified as leading to positive impact, not only by increasing students' achievement, but also by enhancing other complementary and fundamental skills such as motivation, positive interaction, cooperation, leadership, decision-making capabilities, tolerance and trust, and the ability to think critically.

We have adopted this hypothesis and considered that Jigsaw is a good candidate for testing it. We have organized the experiment as follows.

We first defined three expert groups for each of the three subtopics introduced in Section III. Students were organized into four teams with each team consisting of one expert for each subtopic. We formed the expert groups randomly as a way for students to learn how to collaborate, discuss, and debate with any partner (Nooritawati, 2010). Each student was also randomly assigned to a team. As a notation, student C2 from Team 2 was assigned to subtopic $\mathrm{C}$.

\subsection{Jigsaw Phases}

To carry out the Jigsaw activity, students followed the ensuing phases over three consecutive weeks:

1. Every student works individually on his subtopic and delivers a short report to the instructor. Reports are evaluated.

2. During class, students present their findings (on their assigned subtopics) to their team members, who worked on different subtopics, in four simultaneous meetings. Each team meeting thus consists of three presentations covering all the subtopics. Each student is required to make a note of missing points, misunderstandings, etc., from the presentation so as to be able to address them in the future.

3. Students assigned to the same subtopic meet in pairs, i.e. A1+A2, B1+B2, etc. Each pair of students pools their revised material (from their team meetings) and refines it until they converge to the same 
material. They then send their integrated material to the teacher. This results in six reports (two per subtopic) for evaluation.

4. During class, each pair of subtopic-specific students presents the improved material to the larger groups consisting of all the members of their teams (e.g. in mixed team $1 \& 2$, student pairs $\mathrm{A} 1+\mathrm{A} 2$, $\mathrm{B} 1+\mathrm{B} 2$, and $\mathrm{C} 1+\mathrm{C} 2$ ).

5. The four students assigned to each subtopic meet and put together their material for the final version and then send a report for evaluation.

6. In a "plenary" meeting during class, three presentations - one for each subtopic - are made. The instructor also evaluates students based on their oral skills, discussions, and possibly other factors that become apparent during this meeting. This is the only time when the instructor is present for all the activities, as all previous phases occur in parallel presentations during class.

\subsection{Evaluation of the Activity}

Despite the Jigsaw literature indicating all the positive impacts the methodology has on the students, we could not risk treating individuals as statistics to avoid any significant negative impact on the grades of those students who may not find Jigsaw productive for them, we weighted this activity so it only counted $10 \%$ towards the final course grade. . This grade is computed as an average of the following four grades:

1. Report from phase 1 , graded as individual work.

2. Report from phase 3, graded as work in pairs.

3. Report from phase 5, graded as work of the four-author groups.

4. Final class presentation, individual assessment.

It is important to say that none of the students were familiar with the Jigsaw technique; it was a new concept for all of them.

\subsection{Learning Objectives and Competences}

Among the competences of the course (as defined in the course syllabus), the Jigsaw activity addresses the following:

- Knowledge and application of the characteristics, functionalities, and structure of distributed systems, computer networks, and the Internet. Ability to design and implement applications based on this knowledge.

- Analyze complex situations and design strategies to address them.

- Compile and select information efficiently.

- Teamwork.

- Decision-making.

\section{RESULTS}

While the reports and presentations are quantitative measures of how well the students adapted to this method to reach fundamental skills and course competences, the students' own perceptions are equally important. For this reason, we sent a survey to all the students after each presentation. Replies were voluntary. The idea was to try to capture not just a result at a point in time, but also to understand how the students felt about the methodology and their fellow students during this activity, and whether they found Jigsaw motivating. 


\subsection{First Jigsaw Survey}
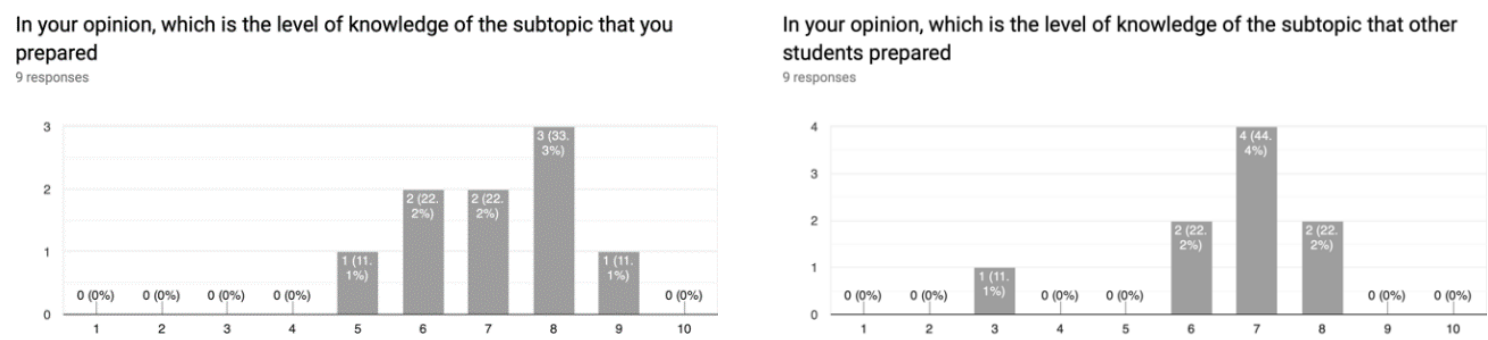

Figure 1. Results from the first survey

From Figure 1, it would seem that students think they are all above average and place their peers into two categories: those who are equally good, (but with a sharper distribution), or those who were very badly prepared. In the results for the question: 'The preparation of your topic is better/equal/worse in relation to the others' topics', 89\% said "equal", and 11\% said "better".

Summary of positive comments (in free text):

Question 1: What aspect of the Jigsaw activity do you like most?

This question elicited free written answers. We summarize the answers below. Noted in bold are the most relevant comments.

1. Having to follow different threads to find the necessary information

2. Teamwork, discussion, and the fact that team members change.

3. The explanations of other students are always more easily understood from the outset because they tend to use words that are less formal than those of the teacher.

4. Conducting the first phases in small groups gives more freedom to speak openly with the other person.

5. Putting together the information synthesized by different people helps one realize that there were things that went unnoticed or that one didn't give them the importance they have.

Summary of negative comments (in free text):

Question 2: What aspect of the Jigsaw activity do you not like?

This question elicited free written answers which we have summarized below and noted in bold the most relevant comment among the answers.

1. Requires too many sessions spent on topics that are not rich/complex enough.

2. Requires a minimum of preparation on part of each student, otherwise one learns very little.

3. The feeling of not being sure whether the information you worked on is good (or that you're not missing information) until you put all the pieces together.

4. It can become quite repetitive explaining everything many times.

5. That we use PBL (project-based learning), the student probably meant "collaborative learning". 


\subsection{Second Jigsaw Survey}

Table 1. Results from the second survey

\begin{tabular}{lcc}
\hline Questions and answers & $\begin{array}{l}\text { After the second session, your } \\
\text { knowledge on the subtopic that on the second session, your knowledge } \\
\text { you prepared has increased: }\end{array}$ & $\begin{array}{l}\text { After the subtopic that your colleagues } \\
\text { prepared has increased }\end{array}$ \\
\hline Some & $33 \%$ & $44 \%$ \\
A little & $56 \%$ & $56 \%$ \\
Did not increase & $11 \%$ & \\
\hline
\end{tabular}

In Table 1 we see that students tend to think that they have learned less from the assembled information during their second meeting of their subtopic than from the second presentations of the other topics. This is a positive result that says that the material that one prepares and discusses is learned quicker (during the first session) than understanding material presented by others but not worked on by oneself.

\subsection{Third Jigsaw Survey}

Summary of positive comments (in free text):

1. Having to prepare the subject by ourselves improved understanding; comparing one's work with the others and putting it together makes one realize what things they hadn't paid much attention to.

2. Easier to understand the subject.

3. You learn the subject you have prepared $100 \%$ after explaining it three times.

4. Being forced to understand and prepare well enough to be able to explain clearly to your colleagues.

Summary of negative comments (in free text):

1. It's a good methodology at the beginning, but it becomes too repetitive if all "experts" in the group summarize more or less the same information.

2. Too many presentations; with a couple it's enough.

3. Some more directed help if we don't find what we need, or we want to find out more.

4. The content of the other students is equal to or worse than that in a traditional class.

5. The level of knowledge is a bit limited due to finding little information online compared to what we could have learned with a traditional method.

6. When taking the exam, it is assumed that there's a level of knowledge about things that some groups may not have discussed. This happened in this exam and I don't think it's OK.

Compared to traditional classes, how was the Jigsaw experience:

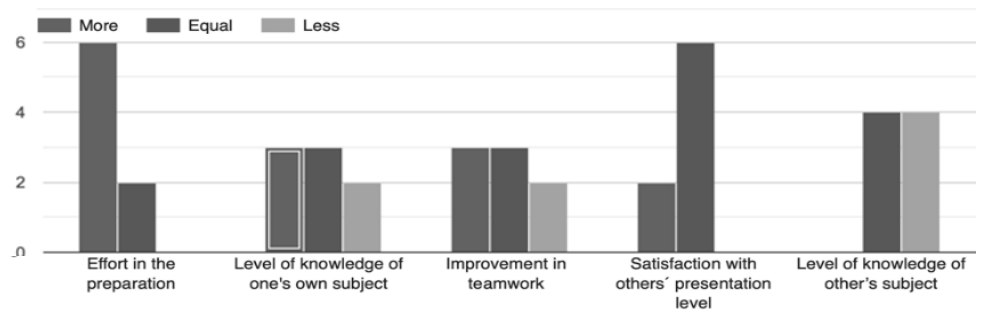

Figure 2. Results from the third survey 
Figure 2 shows that a significant number of students considered that they acquired less knowledge about the subtopics they had not prepared than if they had been taught using a traditional method. We believe that this is linked to the fact that some students also lacked some background to understand whether they covered all the relevant material. One lesson learned is that the teacher may need to provide more directed support in some cases. One possible way to do that would be via quizzes that students could take online for themselves. The points covered in the quizzes would need to cover all the material that the teacher thinks necessary for the students to fully understand the class material - including that which was explained by other students. The results of the quizzes are not seen by the teacher.

As a last thought for interpreting the student answers, these are the impressions as related by the students. Thus, they may, or may not, reflect reality. These results must be taken as an indication rather than a recipe; more work is needed to fully understand this feedback.

\section{CONCLUSION}

This work presents a study with the 12 third year undergraduates registered in the Cloud computing and distributed systems course of the "Design and development of video games" specialization at the University of Girona, Spain. Although this is a technical course in the curriculum, it lends itself to the possibility of learning various topics independently. We chose to implement the Jigsaw methodology to increase students' understanding, motivation, cooperation and leadership skills, decision-making capabilities, tolerance and trust, and their ability to think critically.

Our results show that students valued most the fact that preparing and presenting the material by themselves made them understand the subject really well and - encouragingly - that contrasting and complementing information as part of a group made them discover aspects that they had originally not paid attention to. Small groups also gave them the freedom to speak more openly. Our conclusion was that most students adapted rather well to working in groups.

On the negative side, the main impression was that there were too many presentations for a small amount of material (subtopics). Additionally, some students felt that they were not sure whether the information they discovered by themselves was complete and of good enough quality, and they would have liked to have had some more directed help when they needed it. We think that the first observation they made can be resolved by better adjusting the quantity of material and the number of teams and teammates. The second observation could be addressed by providing some form of self-assessment (for instance, online quizzes) directed towards covering a set of teacher-selected points. This could be a way to support those students who feel they need more guidance in a more problem-directed manner.

Finally, there were some contradictions. Students frequently complain about traditional teaching methods, but when they have to follow an alternative method, some reach the conclusion that the traditional one was in fact better. This may be the result of statistics over a reduced number of data points (i.e. students), a real issue for certain learning styles, or a consequence of the way the questions were formulated in our surveys. In the future we will refine these surveys and apply this method to other courses to obtain more data points, which would allow for a more precise analysis, with better results in the classroom. We will also validate these results with Master students, in an effort to see whether age does seem to play a role in the sense that the literature suggests - that older students find it harder to adapt to more flexible, hierarchy-less environments.

\section{ACKNOWLEDGEMENT}

This work has been partially supported by the Generalitat de Catalunya research support program SGR-1469] and the Ministerio de Economia, Industria, y Competitividad (TIN2016- 78473-C3-2-R). 


\section{REFERENCES}

Aronson, E. 1978. The Jigsaw Classroom, Sage, Beverly Hills, CA, USA.

Dumus, Kilic. 2008. The Effect of the Jigsaw Technique on Learning the Concepts of the Principles and Methods of Teaching. World Applied Sciences Journal, Vol. Supple 1. pp. 108-114.

Felder, R.M., and Silverman, L.K.1988. Learning and teaching styles in engineering education. Engineering Education, 78:4, 674-681. 1988.

Felder, R.M. and Brent, R. 2003. Designing and teaching courses to satisfy ABET Engineering criteria. Journal on Engineering Education. Vol. 92 (1) pp. 7-25.

Guido, M. 2017. All About Inquiry-Based Learning: Definition, Benefits and Strategies. https://www.prodigygame.com/blog/inquiry-based-learning-definition-benefits-strategies/

Jones, L. 2007. The student-centered classroom. Cambridge University Press. Cambridge, UK.

Kousa, Maan. 2015. Jigsaw Cooperative Learning in Engineering Classrooms. IEEE Global Engineering Education Conference (EDUCON).

McConnell, Jeffrey J. 1996. Active learning and its use in computer science. In Proceedings of the 1st conference on Integrating technology into computer science education (ITiCSE '96). ACM, New York, USA, 52-54.

Moreillon, J. 2007. Collaborative strategies for teaching reading comprehension: Maximizing your impact. American Library Association, Chicago, USA.

Nooritawati Md Tahir, Kama Azura Othman. 2010. The Jigsaw Cooperative Method amongst Electrical Engineering Students. 2nd International Congress on Engineering Education. Kuala Lumpur, Malaysia.

Pow-Sang, José Antonio. 2016. The Jigsaw technique to teach object-oriented design: A replication study with graduate students. IEEE Global Engineering Education Conference (EDUCON) pp. 1212-1217.

Sahin, A. 2010. Effects of jigsaw II technique on academic achievement and attitudes to written expression course. Educational Research and Reviews, Vol. 5, pp. 777-787.

Sharan, S. 1980. Cooperative learning in small groups: Recent methods and effects on achievement, attitudes, and ethnic relations. Review of educational research, Vol. 50 (2). pp. 241-271.

Slavin, R. E. 1995. Cooperative learning: Theory, research, and practice. Allyn and Bacon, Boston, USA.

Stuart, J. and Rutherford, R. 1978. Medical Student Concentration During Lectures. The Lancet, Vol. 2, September. pp. 514-516.

Zarei, Abbas Ali and Adbi, Venus. 2016, Blended Learning, Computer-based, and Conventional Reading Instruction Affecting EFL Learners' Self-regulation and Critical Thinking. International Journal of Humanities and Cultural Studies. 